\title{
Novos compósitos de polianilina e exopolissacarídeos com aplicações em biomateriais: uma revisão
}

\section{New composites of polyaniline and polysaccharides with applications as biomaterials: one review}

\author{
Eliana França ${ }^{1}$, Luiz Henrique Dall’ Antonia ${ }^{2}$
}

\begin{abstract}
Resumo
Nesta revisão, mostraremos alguns resultados envolvendo compósitos feitos a partir de polianilina e polissacarideos e suas propriedades como promissores biomateriais. Os estudos de aplicações biomédicas de polímeros condutores têm sido considerados devido ao estímulo elétrico, a diminuição citotoxicidade, a boa biocompatibilidade, entre outras vantagens. A polianilina e os polímeros derivados do anilina receberam atenção nos últimos anos, pela estabilidade química em condições de ambiente diversos, a processabilidade, a facilidade de polimerização e dopagem, o custo baixo e outras propriedades particulares. A botriosferana é um exopolissacarídeo (EPS) classificada no grupo do beta-(1 -3) glucanas, produzido pelo fungo Botryosphaeria Rhodina. O potencial de interação entre os polímeros condutores com ambiente biológico deve ser considerado, devida às possibilidades de aplicação como desenvolvimento de músculos artificiais, estímulo de regeneração de nervos e liberação controlada de medicamentos.
\end{abstract}

Palavras-chave: Polianilina. Polissacarídeo. Compósitos.

\begin{abstract}
In this revision we will show some results involving composites made with polyaniline and polysaccharides and their properties as promising biomaterials. Studies about the biomedical application of conducting polymers have being considered due the electric stimulation, decrease citotoxicity, good biocompatibility, and others. Polyaniline and polymers derived from the aniline has received attention in the last years by chemical stability in environmental conditions, processibility, facility of polymerization and doping, short cost and particular properties. The botryospheran is an exopolysaccharide (EPS) classified in the group of the beta-(1 -3) glucans, produced by the fungus botryosphaeria sp.. EPS has being investigated in parallel about the variability of biological answers of defense. The potential of interaction between conducting polymers with biological environment has been considered, once the application possibilities like development of artificial muscles, nerves regeneration stimulation and medicines delivery control. Key words: Polyaniline. Polysaccharideos. Composites.
\end{abstract}

1 Licenciada em Química - Laboratório de Eletroquímica e Materiais/Depto. Química/CCE/UEL

2 Professor Adjunto - Laboratório de Eletroquímica e Materiais/Depto. Química/CCE/UEL - Email: luizh@uel.br 


\section{Introdução}

O campo de tecidos modificados tem se desenvolvido rapidamente desde a década passada, e muitos esforços em pesquisas paralelas estão atualmente sob caminhos para criar uma vasta variedade de tecidos vivos de substituição para aplicações terapêuticas. O surgimento de futuras tecnologias para engenharia de tecidos deverá requerer o desenvolvimento de novos biomateriais designados para sustentar crescimento físico de tecidos bem como para provocar respostas específicas desejáveis das espécies celulares. Um caminho para atingir esse objetivo é a incorporação de moléculas biológicas em matrizes sintéticas. Especificidade adicional pode ser ganha por escolha de um material de matriz eletroatívo para estimular eletricamente respostas em espécies de células como ossos e nervos.

A síntese de compósitos baseados em polímeros condutores e exopolissácarídeos une a habilidade para estimular eletricamente a regeneração de nervos dos polímeros condutores com as atividades específicas biológicas de alguns exopolissacarídeos. Um biomaterial que possui propriedades elétricas e biológicas deverá ter muitas características benéficas in vivo, incluindo o aumento da angiogênese (desenvolvimento de vasos sangüíneos) nos tecidos como ossos e nervos. Esse desenvolvimento é conhecido por ser beneficiado por estimulação elétrica.

\section{Polímeros Condutores}

Um histórico sobre tecnologia de polímeros evidenciaria, sem dúvida alguma, que uma das propriedades mais importantes destes materiais sintéticos é a capacidade de comportar-se como excelentes isolantes elétricos, tanto para altas frequiências quanto para voltagens. No entanto, nos últimos anos, uma nova classe de polímeros orgânicos tem sido desenvolvida, e sua importância está relacionada à possibilidade de conduzir eletricidade (MAIA et al., 1999). Os polímeros condutores são geralmente chamados de "metais sintéticos" por possuírem propriedades elétricas, magnéticas e ópticas de metais e semicondutores. O mais adequado seria chamá-los de "polímeros conjugados", porque são formados por cadeias contendo duplas ligações $\mathrm{C}=\mathrm{C}$ conjugadas. Essa conjugação permite que seja criado um fluxo de elétrons em condições específicas. Os elétrons $\pi$ da dupla ligação podem ser facilmente removidos ou adicionados para formar um íon, que, neste caso, é polimérico (FAEZ et al., 2000). Interesse evidente é combinar em um mesmo material as propriedades elétricas de um semicondutor ou metal com as vantagens de um polímero (MAIA et al., 1999).

Desde a década de 60, é conhecido que moléculas orgânicas que apresentam duplas ligações conjugadas podem exibir propriedades semicondutoras. O desenvolvimento inicial foi inibido pelo fato que as cadeias rígidas, em uma estrutura conjugada, também produzem uma intratabilidade extrema, tal que a maioria dos primeiros exemplos de polímeros condutores eram infusíveis, insolúveis e, portanto, de pouco valor tecnológico. A descoberta dos polímeros condutores teve início no começo dos anos 70. O primeiro polímero condutor foi obtido em 1977, pela exposição do poliacetileno na forma isolante a agentes dopantes, oxidantes ou redutores, tornando-o condutor elétrico intrínseco (MATTOSO, 1996). O poliacetileno tratado com ácido ou base de Lewis, teve aumento da condutividade em até 13 ordens de grandeza (MAIA et al., 1999).

A oxidação/redução da cadeia polimérica é efetuada por agentes de transferência de carga (aceptores/doadores de elétrons), convertendo o polímero de isolante em condutor ou semicondutor. Esses agentes são chamados de "dopantes" em analogia com a dopagem dos semicondutores, porém são adicionados em quantidades muito superiores, pois a massa do dopante pode chegar a até $50 \%$ da massa total do composto. Nos semicondutores inorgânicos, a condutividade só é alcançada pela inserção de elementos (dopantes) que possam doar ou receber 
elétrons a fim de proporcionar um fluxo de elétrons e assim gerar portadores de corrente elétrica (FAEZ et al., 2000).

A reação de dopagem envolve um processo de transporte de carga no qual sítios do monômero (unidade que se repete na estrutura do polímero) no estado oxidado e contra-íons compensadores de carga se difundem através do filme polimérico. A reação de oxidação pode ser efetuada tanto por aplicação de potencial apropriado como também usando um agente químico oxidante, porém, neste caso é o agente oxidante que se difunde pelo polímero (ROVER; OLIVEIRA; KUBOTA, 1997).

Em alguns processos, a dopagem é simultaneamente protônica e oxidativa, como no caso de alguns polímeros como a polianilina. Essas reações redox proporcionam aumento da mobilidade dos elétrons e também da condutividade (ROVER; OLIVEIRA; KUBOTA, 1997).

$\mathrm{Na}$ maioria dos polímeros condutores, como polipirrol e politiofeno, o processo de dopagem ocorre simultaneamente com a oxidação da cadeia. Elétrons são retirados da cadeia durante oxidação e há inserção de contra-íons (dopantes) para balancear a carga. Os mais conhecidos aceptores e doadores de elétrons, incluindo-se agentes fortes e fracos, são: $\mathrm{AsF}_{5}, \mathrm{I}, \mathrm{BF}_{3}, \mathrm{HF}, \mathrm{Li}, \mathrm{Na}$ e $\mathrm{K}$, respectivamente. O processo de dopagem pode ser realizado por métodos químicos ou apenas pela exposição dos polímeros condutores aos vapores dos agentes de transferência de carga (ROVER; OLIVEIRA; KUBOTA, 1997).

Os polímeros intrinsecamente condutores (PIC) têm atraído a atenção de inúmeros grupos de pesquisa, desde a sua descoberta, tanto pela importância científica em se entender este novo fenômeno, como pelo seu potencial em aplicações tecnológicas (MATTOSO, 1996).

\section{Polianilina}

A polianilina e polímeros derivados da anilina (Figura 1) têm recebido grande atenção nos últimos anos pela sua estabilidade química em condições ambientais, processabilidade, facilidade de polimerização e dopagem, baixo custo e suas propriedades únicas (MATTOSO, 1996; ABULQUERQUE, et al. 2004).

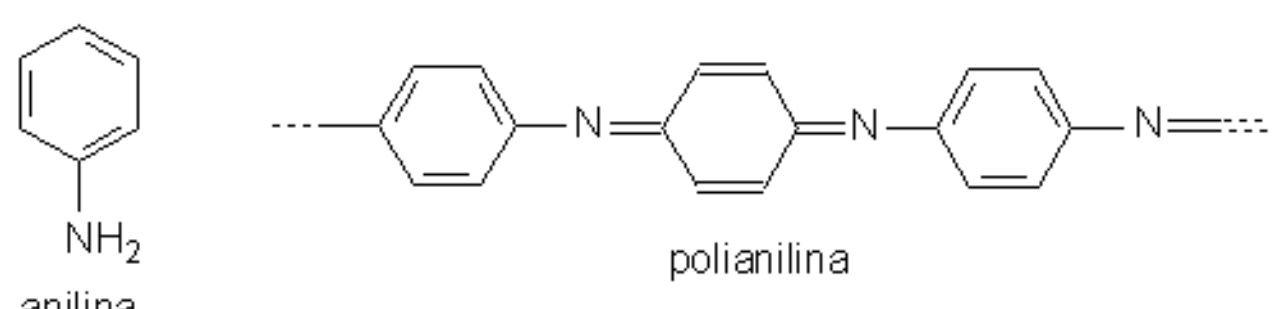

Figura 1. Estrutura da anilina e polianilina

A polianilina forma uma nova classe de polímeros condutores, porque pode ser dopada por protonação, isto é, sem que ocorra alteração no número de elétrons (oxidação ou redução) associados à cadeia polimérica. O grau de protonação da base depende do grau de oxidação que o polímero foi sintetizado, e do pH da solução dopante (MATTOSO, 1996; PAULIUKAITE; BRETT; MONKMAN, 2004, NAGARALE, et al. 2004).
A polianilina pode ocorrer em diferentes estados de oxidação, dos quais a forma esmeraldina, 50\% oxidada, é a mais estável, a forma base esmeraldina (isolante) do polímero pode reagir com ácidos $(\mathrm{HCl})$ resultando na forma sal esmeraldina (condutora). A reação de protonação ocorre principalmente nos nitrogênios imínicos da polianilina (-N=).Este estado contém duas unidades repetitivas, a amina-fenileno e a iminaquinona. Além da elevada condutividade 
elétrica, que chega à ordem de $10^{2} \mathrm{~S} \mathrm{~cm}^{-1}$, outra propriedade interessante da polianilina é exibir diferentes colorações em variadas condições de $\mathrm{pH}$ ou o potencial elétrico (FAEZ et al., 2000).

\section{Síntese de Polímeros Condutores}

Os polímeros condutores podem ser sintetizados por tres métodos de polimerização: químico, eletroquímico e fotoeletroquímico. Dentre esses métodos, a síntese química é a mais utilizada e industrialmente é a mais vantajosa por possibilitar a produção de grandes quantidades de material. Algumas rotas de síntese são muito simples e podem ser adaptadas para escala piloto ou industrial (poli(pfenilvinileno), polipirrol e polianilina). Outras requerem ambientes isentos de umidade (polifenilenos e politiofenos). O produto da oxidação da anilina foi primeiramente preparado em 1862, porém suas propriedades foram reconhecidas somente cerca de 100 anos depois (década de 80 do século 20), despertando um interesse particular devido ao baixo custo de produção, facilidade de síntese e alto rendimento (FAEZ et al., 2000).

\section{Síntese Química}

A síntese química da polianilina pode ser conduzida utilizando-se uma variedade de agentes oxidantes $\left(\left(\mathrm{NH}_{4}\right)_{2} \mathrm{~S}_{2} \mathrm{O}_{8}\right), \mathrm{MnO}_{2}, \mathrm{Cr}_{2} \mathrm{O}_{4}, \mathrm{H}_{2} \mathrm{O}_{2}$, $\mathrm{K}_{2} \mathrm{Cr}_{2} \mathrm{O}_{7}, \mathrm{KClO}_{3}$ ), e meios ácidos (inorgânicos: $\mathrm{HCl}$, $\mathrm{H}_{2} \mathrm{SO}_{4}, \mathrm{H}_{2} \mathrm{PO}_{4}, \mathrm{HClO}_{4}, \mathrm{HPF}_{6}$, poliácidos como, poli(vinil sulfônico) - PVS e poli( estireno sulfônico)

- PSS e ácidos funcionalizados como, cânforssulfônico - CSA e dodecilbenzeno sulfônico - DBSA). O sistema mais comum é o peroxidissufato de amônio em soluções aquosas de $\mathrm{HCl}$ com $\mathrm{pH}$ entre 0 e 2 (MATTOSO, 1996; PARK; CHO; CHOI, 2004; PROKES; STEHSKALB, 2004; SMERTENKOA, et al. 2004).

\section{Síntese Eletroquímica}

Os polímeros condutores também podem ser depositados eletroquimicamente na forma de filmes sobre eletrodos metálicos ou semicondutores. A célula eletroquímica consiste de um eletrodo de trabalho (o eletrodo no qual o filme do polímero vai ser depositado), um contra-eletrodo e um eletrodo de referência. Esses são imersos em uma solução que contenha o monômero e o eletrólito (os ânions dopantes). No caso da anilina, necessário acidificar o meio. O meio reacional pode ser aquoso ou orgânico, dependendo da solubilidade do precursor polimérico e da estabilidade do produto. As dimensões do filme formado são limitadas pela área geométrica do eletrodo e pela densidade de carga utilizada na síntese. Industrialmente, esta técnica é utilizada na preparação de filmes poliméricos para a produção de baterias recarregáveis ou para polimerização in situ, utilizandose outros materiais como matriz (FAEZ et al., 2000; SAÇAK; AKBULUTT; BATCHELDER, 1998).

A síntese eletroquímica possui, sob a síntese química da polianilina, as vantagens de não necessitar de agente oxidante e catalisador; ter facilidade de caracterização "in situ" por técnicas espectroscópicas; e o polímero ser obtido diretamente na forma de filmes finos (MATTOSO, 1996, SAÇAK; AKBULUTT; BATCHELDER, 1998).

Devido à facilidade e versatilidade dos métodos de síntese da polianilina e seus derivados, esta pode ser preparada para apresentar características específicas dependendo do dopante e/ou das condições utilizadas (MATTOSO, 1996; PARK; CHO; CHOI, 2004; PROKES; STEHSKALB, 2004; SMERTENKOA, et al. 2004).

\section{Aplicações dos Polímeros Condutores}

Uma das grandes vantagens dos polímeros é a sua facilidade de processamento em artefatos de diferentes formas e tamanhos, característica essencial para viabilizar aplicações tecnológicas. Isso requer polímeros que sejam solúveis ou fusíveis e termicamente estáveis. Nesse aspecto, a polianilina tem-se destacado entre os polímeros condutores, devido à sua solubilidade e à possibilidade de 
processamento a quente. Com isso ela pode ser processada por uma variedade de técnicas, dentre as quais se salientam: filmes por solução; filme-gel; filmes depositados por via eletroquímica; fiação por solução; polimerização química in situ; blendas poliméricas com polímeros convencionais; técnica de Langmuir-Blodgett; técnica de automontagem (MATTOSO, 1996).

Desde a descoberta, os polímeros intrinsecamente condutores têm, sobretudo em química analítica, aplicações na construção de novos sensores. Alguns exemplos de aplicações destes polímeros condutores, são a fabricação de baterias recarregáveis, dispositivos eletrocrômicos onde a reação direta de oxidação é responsável pela mudança na coloração das espécies em solução, diodos emissores de luz, proteção contra corrosão, recobrimento de materiais além da construção de sensores químicos e térmicos voltados à monitoração analítica (ROVER; OLIVEIRA; KUBOTA, 1997).

Aplicações biomédicas para polímeros condutores estão atualmente sendo consideradas, incluindo o desenvolvimento de músculos artificiais, controle para liberação de fármacos e estimulação para regeneração de nervos. Baixa citotoxicidade e boa biocompatibilidade são evidências para o crescimento de células em polímeros condutores e o baixo grau de inflamação visto em testes com animais em períodos de várias semanas (TANAKA; KATSUURA; TORII, 1997). O potencial de interação entre polímeros com meio biológico necessita ser cuidadosamente considerado (KILMARTIN et al., 2004).

\section{Expolissacarídeos}

Polissacarídeos, também chamados glicanas, são macromoléculas naturais encontradas em todos os organismos vivos, constituindo um grupo de compostos dos mais abundantes e importantes da biosfera, como, por exemplo, celulose e amido nas plantas e glicogênio dos animais. Os exopolissacarídeos (EPS) são definidos como polissacarídeos extracelulares, produzidos por alguns fungos e bactérias, os quais são encontrados ligados à superfície das células ou são excretados para o meio extracelular, na forma de limo (SUTHERLAND, 1998; STELUTI et al. 2004).

Muitas bactérias são exploradas para produção comercial de polissacarídeos, o qual encontra aplicações em produtos alimentícios, cosméticos e farmacêuticos (BARBOSA et al., 2004).

Nos fungos, os EPS constituem uma importante percentagem da biomassa, participando com mais de 75\% dos polissacarídeos constituintes da parede da hifa (BARBOSA et al., 2004). EPS que são gomas solúveis em água, produzidos por uma ampla variedade de microrganismos, possuem propriedades físicas peculiares, que favorecem o emprego nas indústrias alimentícias, farmacêuticas, petrolíferas, entre outras (GIESE et al., 2003).

A maioria dos EPS fúngicos são $\beta$-glucana. As propriedades físicas e fisiológicas dos polissacarídeos são determinadas pelas diferenças químicas tais como: tipo de ligação glicosídica, grau de ramificação e composição monossacarídica (GUTIÉRREZ; PIETRO; MARTINÉZ, 1996). Grandes variações no grau de ramificação desses polímeros podem afetar a sua solubilidade (SUTHERLAND, 1998).

\section{Botriosferana}

O EPS botriosferana é produzido pelo fungo ascomiceto Botryosphaeria rhodina é isolado do fluído extracelular por precipitação com etanol.

Os fungos Botryosphaeria sp. são reconhecidos como patógenos de plantas, e causam várias doenças em plantas de importância comercial. Botryosphaeria sp. Demonstra-se ligninolítico, produzindo enzimas que degradam parede celular lignificada de plantas (BARBOSA et al., 2003).

$O$ EPS botriosferana possui estrutura $(1 \rightarrow 3 ; 1 \rightarrow 6)$ - $\beta$-D-glucana (figura 2 ), este tipo de complexo polissacarídico é considerado útil em imunoterapias (BARBOSA et al., 2003). 


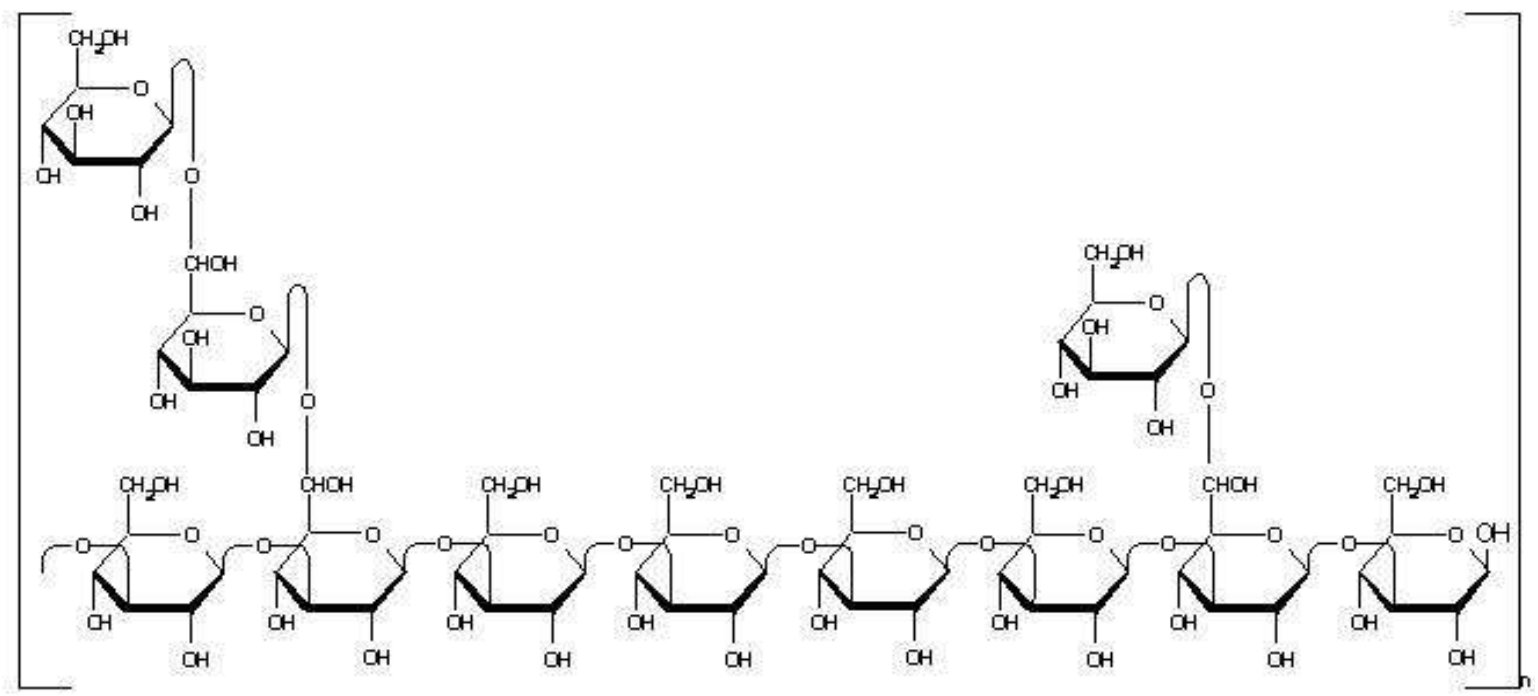

Figura 2. Esquema da estrutura da botriosferana.

\section{Síntese de Exopolissacarídeos}

A composição do meio e as condições de cultivo interferem diretamente na produção dos EPS microbianos. Os microrganismos são adaptados ao meio ambiental natural onde vivem, pois nele existem fatores limitantes como fontes de carbono e nitrogênio, aeração, agitação, microelementos entre outros, e isso confere a eles um estado de homeostase (BARBOSA et al., 2004).

$\mathrm{Na}$ produção de EPS por fungos, deve ser considerada a cepa fúngica escolhida como também o seu meio ambiente natural para adequar, em laboratório, o meio de cultivo em termos de características nutricionais (BARBOSA et al., 2004).

\section{Aplicações de Exopolissacarídeo Fúngico}

As aplicações biotecnológicas dos polissacarídeos são limitadas devido aos problemas relacionados com as modificações físicas, químicas e enzimáticas, que são necessárias para o desenvolvimento de novos produtos. Técnicas de fermentação e biotecnologia têm sido desenvolvidas com o objetivo de sintetizar e modificar carboidratos, sendo baseadas essencialmente no uso de polissacarídeos. No entanto, há dificuldades em tornar alguns processos economicamente viáveis e também de se obter enzimas específicas para a conversão de determinados substratos (GIESE et al., 2003).

Vários EPS produzidos por microrganismos ainda não foram adequadamente explorados e somente poucos têm sido produzidos em larga escala. Muitos polissacarídeos produzidos por bactérias e fungos possuem propriedades semelhantes à do agar. Outros possuem propriedades reológicas que são valiosas para o emprego industrial. Entre os polissacarídeos microbianos com usos comerciais podem ser citados xantana, dextrana, alginato, curdlana e gelana, produzidos por bactérias e o escleroglucana e pululana, produzido por fungos (BARBOSA et al., 2004).

Os EPS microbianos são bastante conhecidos por suas propriedades espessantes, estabilizantes, emulsificantes, geleificantes entre outras (ROBERTS; KIMMEL; ZIEGLER, 1998). Porém outra possibilidade de aplicação destes biopolímeros é a saúde humana. Várias pesquisas sobre polissacarídeos fúngicos têm-se concentrado em aplicá-los como agentes anti-tumorais (MAZIERO et al., 1999). Os polissacarídeos que apresentam esta atividade são todos glucanas intimamente relacionados à estrutura do escleroglucana (YANG; LIAU, 1998). 
EPS derivados de fungos, especialmente basidiomicetos, eram usadas na medicina tradicional chinesa e japonesa para tratar determinadas doenças incluindo câncer. EPS de vários fungos tem demonstrado possuir interessantes atividades biológicas como anti-tumoral, anti-inflamatória e imunomodulação (BARBOSA et al., 2003).

As aplicações terapêuticas dos expolissacarídeos dependem das propriedades físicas, conformação espacial e das propriedades reológicas específicas de cada macromolécula. Entre as aplicações estudadas estão envolvidas atividades imunomoduladora, antitumoral, anti-hepatite, antiHIV, antiviral entre outras (GIESE et al., 2003).

\section{Compósitos Baseados em Polímero Condutor / Exopolissacarídeo e suas Aplicações}

Compósitos são materiais constituídos por uma mistura de dois ou mais componentes ou fases distintas, usualmente combinados em escala macroscópica, os quais devem estar presentes em proporções razoáveis (JOSÉ; PRADO, 2005). Pouco se tem estudado sobre a utilização de compósitos baseados em polímero condutor e EPS, porém suas aplicações de formas separadas são bem investigadas e comprovadamente eficientes (YUAN, LIAU, 2002).

Dentre os polímeros condutores, o polipirrol é o mais empregado em pesquisas de biomateriais. COLLIER et al., 2000 sinterizaram e caracterizaram compósito de polipirrol-ácido hialurônico (PP/HA) para aplicações de engenharia de tecidos e verificam que este biomaterial é um candidato promissor para aplicações de tecidos modificados e em cicatrização de ferimentos, pois pode beneficiar a estimulação elétrica e o aumento de vascularização.

Outros biomateriais contendo polímeros condutores e outros compostos também estão sendo estudados. Filmes de variadas formas da polianilina copolimerizada com ácido acrílico e imobilizada com colágeno foram implantados em ratos por um período de 19 a 50 semanas e avaliou-se a resposta de tecido in vivo para teste de biocompatibilidade, após o período de investigação, o filme de esmeraldinaimobilizada com colágeno, não apresentou características de imcompatibilidade dos tecidos próximo ao implante (WANG et al., 1999). A anilina e a polianilina também foram avaliadas como agentes antioxidantes, e mostrou ser bom agente redutor e eliminou radicais livres similarmente aos antioxidantes fenólicos presentes em várias frutas e bebidas (KILMARTIN et al., 2004) e (GIZDAVICNIKOLAIDIS et al., 2004).

Outros estudos de biomateriais contendo polianilina, envolve a síntese de compostos polianilina polimerizada separadamente com alguns diferentes ácidos como ácido clorídrico, sulfônico e fenilfosfônico e incorporada a um biosensor condutométrico usado na detecção do vírus da diarréia viral bovina (ALOCILJA; TAHIR; GROOMS, 2005).

Devido à vasta aplicabilidade dos biomateriais incluindo compósitos: polímero condutor/EPS, estes precisam de maior atenção dos pesquisadores. Desse modo, podem ser descobertas muitas outras características específicas e aplicações importantes para estes materiais.

\section{Referências}

ALBUQUERQUE, J. E.; MATTOSO, L. H. C.; FARIA, R. M., MASTERS, J. G., MACDIARMID, A. G. Study of the interconversion of polyaniline oxidation states by optical absorption spectroscopy. Synthetic Metals, Ohio, v.146, n.1, p.1-10, 2004.

ALOCILJA, E. C.; TAHIR, Z. M.; GROOMS, D. L. Polyaniline sunthesis and its biosensor application. Biosensors \& Bioeletronics, Silsoe, v.20, n.8, p.1690-1695, 2005.

BARBOSA, A. M.; STELUTI, R. M.; DEKKER, R. F. H.; CARDOSO, M. S; CORRADI DA SILVA, M. L. Structural characterization of Botryosphaeran: a $(1 \circledast 3 ; 1 \circledast 6)-b-D-$ glucan produced by the ascomyceteous fungus, Botryosphaeria sp. Carbohydrate Research, Tennessee, v.338, n.16, p.1691-1698, 2003. 
BARBOSA, A. M.; CUNHA, P. D. T.; PIGATTO, M. M.; CORRADI da SILVA, M. L. Produção e Aplicações de Exopolissacarídeos Fúngicos. Semina: Ciências Exatas e Tecnológicas, Londrina, v.25, n.1, p.29-42, 2004.

BOROLE, D. D.; KAPADI, U. R.; MAHULIKAR, P. P.; HUNDIWALE, D. G. Electrochemical behaviour of polyaniline, poly(o-toluidine) and their copolymer in organic sulphonic acids. Materials Letter, Fukuoka, v.58, p.3816-3822, 2004.

COLLIER, J. H.; CAMP, J. P.; HUDSON, T. W.; SCHMID, C. E. Synthesis and characterization of polypyrrole/ hyaluronic acid composite biomaterials for tissue engineering apllications. Journal Biomedical Materials Research, v.50, n.4, p.574-584, jun. 2000.

FAEZ, R.; REIS, C.; SCANDIUCCI, P., KOSIMA, O.; RUGGERI, G.; PAOLI, M. Polímeros Condutores. Química Nova na Escola, São Paulo, n.11, p.13-18, 2000.

GIESE,E.C.;BARBOSA, A. M.; CORRADIDA SILVA, M.L. Glucanases Fúngicas. Revista Biotecnologia Ciência e Desenvolvimento, Brasília, ed. 30, p.97-103, 2003.

GIZDAVIC-NIKOLAIDIS, M.; TRAVAS-SEJDIC, J; KILMARTIN, P. A.; BOWMAKER, G. A.; COONEY, R. P. Evaluation of antioxidant activity of aniline and polyaniline. Current Apllied Physics, Korea, v.4, p.343346, 2004.

GUTIÉRREZ, A.; PIETRO, A.; MARTINEZ, A. T. Structural characterization of extracellular polysacharides produced by fungi from the genus Pleurotus. Carbohydrate Research, Tennessee, v.281, p.143-154, 1996.

JOSÉ, N. M.; PRADO, L. A. S. Materiais híbridos orgânicoinorgânicos: preparação e algumas aplicações. Química Nova, São Paulo, v.28, n.2, p.281-288, 2005.

KILMARTIN, P;; GIZDAVIC-NIKOLAIDIS, M; TRAVASSEJDIC, J; BOWMAKER, G; COONEY, R; THOMPSON, C. The antioxidant activity of conducting polymers in biomedical applications. Current Applied Physics, Korea, v.4, p.347-350, 2004.

MAIA, J. D.; DE PAOLI, M.; ALVES, O. L.; ZARBIN, A. J. G.; NEVES, S. Síntese de polímeros condutores em matrizes sólidas hospedeiras. Química Nova, São Paulo, v.23, n.2, p.204-215, 2000.

MATTOSO, L. H. Polianilinas: síntese, estrutura e propriedades. Química Nova, São Paulo, v.19, n.4, p.388399, 1996.

MAZIERO, R.; CAVAZZONI, V.; BONONI, V. L. R. Screening of Basidiomycetes for the production of exopolysaccharide and biomass in submerged culture. Revista de Microbiologia, São Paulo, v.30, p.77-84, 1999.
NAGARALE, R. K.; GOHIL, G. S; SHAHI VINOD, K; TRIVEDI, G. S; RANGARAJAN, R. Preparation and electrochemical characterization of cation- and anionexchange/polyaniline composite membranes. Journal of Colloid and Interface Science, Chicago, v.277, n.1, p.162171, 2004.

PARK, S. Y; CHO, M. S.; CHOI, H. J. Synthesis and electrical characteristics of polyaniline nanoparticles and their polymeric composite. Current Applied Physics, Korea, v.4, p.581-583, 2004.

PAULIUKAITE, R.; BRETT, C. M. A.; MONKMAN, A. P. Polyaniline fibres as electrodes. Electrochemical characterisation in acid solutions. Electrochimica Acta, Milan, v.50, p.159-167, 2004.

PROKES, J; STEJSKALB, J. Polyaniline prepared in the presence of various acids 2. Thermal stability of conductivity. Polymer Degradation and Stability, Brighton, v 86, p. 187-195, 2004.

ROBERTS, R. F.; KIMMEL, S. A.; ZIEGLER, G. R. Otimization of Exopolisaccharide Production by Lactobacillus delbrueckii subsp. Bulgaricus RR Grown in a Semidefined Medium. Applied and Environmental Microbiology, Washington, v.64, n.2, p.659-664, 1998.

ROVER, L. J; OLIVEIRA, G.; KUBOTA, L. Transdutores potenciométricos a base de polímeros condutores: aplicações analíticas. Química Nova, São Paulo, v.20, n.54, p.519-527, 1997.

SAÇAK, M.; AKBULUTT, U.; BATCHELDER, D. Characterization of electrochemically produced, twocomponent films of conducting polymers by Raman microscopy. Polymer, Bayreuth, v.39, n.20, p.4735-4739, 1998.

SMERTENKOA, P. S.; DIMITRIEVA, O. P.; SCHRADERB, S.; BREHMERB, L. Doping of polyaniline by transition metal salts: current-voltage characteristics of the ITO/ polymer film/metal heterostructures. Synthetic Metals, Ohio, v.146, p.187-196, 2004.

SUTHERLAND, J. W. Novel and established applications of microbial polysaccharides. Trends in Biotechnology, London, v.16, p.41-46, 1998.

STELUTI, R. M.; GIESE, E. C.; PIGGATO, M. M.; SUMIYA, A. F. G.; COVIZZI, L. G.; JOB, A. E.; CARDOSO, M. S.; CORRADIDA SILVA, M.L.;DEKKER, R.F.H.;BARBOSA, A. M. Comparison of Botryosphaeran production by the ascomyceteous fungus Botryosphaeria sp., grown on different carbohydrate carbon sources, and their partial structural features, Journal of Basic Microbiolopgy, Weinheim, v.44, n.6, p.480-486, 2004. 
TANAKA, H.; KATSUURA, H.; TORII, S. Electropolymerization of anilines linked with triarylamines as a redox-active function. Electrochimica Acta, Milan, v.42, n.13-14, p.2019-2026, 1997.

YANG, F-C.; LIAU, G-B. The influence of environmental conditions on polysaccharide formation by Ganoderma lucidum in submerged cultures. Process Biochemistry, v.33, p.547-553, 1998.
YUAN, G-L; KURAMOTO, N; SU, S-J. Template synthesis of polyaniline in the presence of phosphomannan. Synthetic Metals, Ohio, v.129, p.173-178, 2002.

WANG, C. H.; DONG, Y. Q.; SENGOTHI, K.; TAN, K. L.; $\mathrm{KANG}$, E. T. In -vivo tissue response to polyaniline. Synthetic Metals, Ohio, v.102, p.1313-1314, 1999. 